\title{
EVALUASI SISTEM INFORMASI DOSEN PADA ITB STIKOM BALI MENGGUNAKAN METODE (PIECES) PERFORMANCE INFORMATION ECONOMICS CONTROL EFFICIENCY AND SERVICE
}

\author{
I W. Bandem Wahyu Pratama Niarta ${ }^{1}$, I Made Candiasa ${ }^{2}$, Sariyasa $^{3}$ \\ 1,2,3 Ilmu Komputer, Universitas Pendidikan Ganesha Singaraja, Indonesia \\ email: bandem.wahyu7793@gmail.com ${ }^{1}$, candiasaimade@yahoo.co.id $^{2}$, sariyasa@undiksha.ac.id ${ }^{3}$
}

\begin{abstract}
Abstrak
ITB STIKOM BALI adalah salah satu instansi pendidikan yang telah menggunakan sistem informasi dosen dalam membantu pekerjaan. Akan tetapi masih terdapat beberapa kendala, seperti belum diketahui mengenai kepuasan para dosen dalam menggunakan sistem informasi dosen. Penelitian ini difokuskan pada analisis evaluasi mengukur kepuasan menggunakan sistem informasi dosen. Populasi penelitian ini mencakup seluruh dosen aktif yang menggunakan sistem informasi dosen sebanyak 155 orang dan 99 terpilih sebagai sampel dengan teknik Simple Random Sampling. Pengumpulan data dilakukan dengan memberikan kuesioner kepada seluruh sampel dan yang mengembalikan sebanyak 93 orang. Teknik yang digunakan untuk mengevaluasi sistem informasi dosen adalah metode PIECES yang memiliki fokus 6 variabel yaitu performance, information, economic, control, efficiency, dan service. Untuk mengukur tingkat kepuasan pengguna dari masing-masing variabel, teknik kuesioner dengan 17 butir pernyataan menggunakan skala likert. Hasil analisis data menunjukkan bahwa untuk semua variabel, rata-rata kepuasan berada pada rentangan nilai 3,4 -4,91 dengan kategori puas. Secara rinci rata-rata skor kepuasan setiap variabel adalah 4,19 untuk performance, 4,16 untuk information, 4,26 untuk economic, 3,85 untuk control, 4,23 untuk efficiency, dan 4,21 untuk service. Berdasarkan temuan tersebut dapat disimpulkan bahwa dosen merasa puas dalam menggunakan sistem informasi dosen. Kendati demikian masih perlu dilakukan revisi untuk penyempurnaan sistem informasi dosen. Direkomendasikan untuk merevisi komponen yang memiliki skor di bawah rata-rata kepuasan pada setiap variabel dan sub variabel PIECES yang digunakan dalam penelitian ini.
\end{abstract}

Kata kunci: Sistem Informasi Dosen, PIECES, Performance, Information, Economics, Control, Efficiency, Service, System Information.

Abstract

ITB STIKOM BALI is one of the educational institutions that has used lecturer information systems in helping their work. However, there are still some obstacles; such as unclear satisfaction in using the lecturer information system. This research is focused on evaluation analysis measuring satisfaction. The population of this study includes all active lecturers who use the lecturer information system as many as 155 people, and 99 were selected as samples with the Simple Random Sampling technique. Data was collected by giving questionnaires to all samples and 93 people returned. The technique used to evaluate the lecturer information system is the PIECES method which focuses on 6 variables, namely performance, information, economic, control, efficiency, and service. To measure the level of user satisfaction of each variable, a questionnaire with 17 statements uses a Likert scale. The results of data analysis show that for all variables, the average satisfaction is in the range of values from 3.4 to 4.91 . In detail, the average satisfaction score for each variable is 4.19 for performance, 4.16 for information, 4.26 for economics, 3.85 for control, 4.23 for efficiency, and 4.21 for service. Based on these findings, it can be concluded that the lecturers are satisfied in using the lecturer information system. However, revisions are still needed to improve the lecturer information system. It is recommended to revise the component that has a score below the average satisfaction on each PIECES variable and sub-variable used in this study.

Keywords : Lecturer Information Systems, PIECES, Performance, Information, Economics, Control, Efficiency, Service, System Information.

Diterima Redaksi: 02-06-2021 | Selesai Revisi: 17-11-2021 | Diterbitkan Online: 31-12-2021

DOI: https://doi.org/10.23887/janapati.v10i3.34973 


\section{PENDAHULUAN}

Kecanggihan terhadap teknologi pada era ini telah banyak sekali diciptakan untuk tujuan memudahkan manusia menyelesaikan pekerjaan dan dalam melakukan aktifitasnya. Seiring dengan teknologi yang semakin pesat dan terus adanya perkembangan, teknologi yang semakin meningkatpun sudah hampir menjadi kebutuhan manusia dalam bekerja, salah satu contoh dari berkembang pesatnya teknologi tersebut adalah sistem informasi. Sistem informasi itu sendiri adalah ciptaan manusia dengan tujuan untuk mencapai penyajikan berbagai informasi yang lebih terstruktur, tepat, akurat dan bermanfaat bagi penggunanya. Seiring dengan era tumbuh kembang teknologi saat ini, pengiriman data dan penyimpanan datapun dapat dilakukan semakin mudah yang diiringi dengan kualitas yang juga turut membaik, baik personal, instansi, hingga kepemerintahanpun turut serta memanfaatkan perkembangan teknologi informasi ini pada pekerjaannya masing-masing. Pada dunia pendidikan, yaitu di Indonesia khususnya saat ini, perlahan hampir seluruh komponen lembaga pendidikan terutama perguruan tinggi diharapkan menyiapkan diri sesegera mungkin dengan menyiapkan semua sarana dan prasarana pemanfaatan teknologi informasi tersebut. Dosen merupakan salah satu bagian yang sangat penting disetiap organisasi instansi pendidikan pada perguruan tinggi, seperti tanggung jawab, tugas, dan peran kinerja dosen dinilai begitu berpengaruh disetiap tujuan pengembangan pendidikan kedepannya, yakni seperti meningkatkan kualitas diri manusia dan serta merta mencerdaskan generasi penerus bangsa Indonesia. Hal tersebut dilakukan guna untuk meningkatkan kualitas dosen pendidik tersebut, maka untuk keprofesional sangatlah diperlukan. Mendistribusi secara proporsional dan terukur pelaksanaan beban kinerja, tugas, dan kewajiban dosen sangatlah diperlukan peninjauan dan pelaporan yang berkala kepada para pejabat kepentingan institusi sebagai bentuk bukti, tanggung jawab kinerja, dan keprofesionalan dosen.

Pada era seperti sekarang ini mulailah para perguruan tinggi diseluruh dunia dan Indonesia khususnya membuat sistem informasi dosen untuk menunjang dan memudahkan kinerja dosen dalam bekerja. Sistem informasi dosen diharapkan memmudahkan dosen untuk mendapatkan dan mengetahui informasi keperluan beban kerja dan pekerjaan-pekerjaan lainnya. Pada Institut Teknologi dan Bisnis STIKOM BALI, sistem informasi dosen ini berisi fitur - fitur tentang semua kegiatan - kegiatan perkuliahan dan jadwal kegiatan akademis lainnya dari semua dosen yang terdapat pada ITB STIKOM BALI, dan juga berisi fitur - fitur tentang semua data dan kegiatan mahasiswa terkait.

Meskipun termasuk golongan institusi pendidikan bidang komputer namun masih ada ditemui beberapa kendala dari penerapan sistem informasi dosen seperti belum diketahuinya kepuasan pengguna menggunakan sistem informasi dosen, serta dari semua pengguna masih adanya sebagian yang belum paham memanfaatkan semua fiturfitur saat menggunakan sistem informasi dosen dikarenakan pada ITB STIKOM Bali juga memiliki mata kuliah yang tidak berbasis teknologi informasi (TI) seperti agama, kewirausahaan, seni budaya dan yang lainnya, dan para dosen yang mengajar mata kuliah tersebut sebagian besar adalah dosen non TI. Selain belum pernahnya dilakukan penelitian evaluasi terhadap sistem informasi dosen dengan menggunakan metode PIECES, metode ini juga memberikan pengalaman yang berbeda saat diterapkan pada penelitian ini, metode PIECES berkerja dengan mengelompokan setiap variabel dan sub variabel yang dimana mempermudah analisis saat penghitungan, evaluasi hasil dan penghitungan nilai dibawah rata-rata untuk pemberian rekomendasi, yang dimana saat menemukan hasil pada analisis dibawah nilai kriteria rata-rata dapat terlihat masalahnya pada variabel dan sub variabel tertentu karena sudah dikelompokan serta dapat dikaji ulang pada variabel dan sub variabel tersebut. Penelitian ini dilakukan agar diperoleh hasil analisis terhadap evaluasi pengukuran dari tingkat kepuasan memahami tampilan, ketepatan dan keakuratan informasi, keekonomisan, kontrol keamanan, keefisienan, dan kualitas layanan dari menggunakan sistem informasi dosen pada ITB STIKOM BALI yang nantinya menghasilkan rangkuman rekomendasi untuk perbaikan kepada pihak pengembang sistem yang diharapkan menambah kualitas sistem informasi dosen pada ITB STIKOM BALI menjadi lebih baik lagi.

Sistem informasi dosen itu sendiri sudah digunakan sejak 2013 di ITB STIKOM BALI, tetapi hanya dua kali pernah dilakukannya penelitian terhadap sistem informasi dosen yang dimana dilakukan pengukuran tingkat kepuasan pengguna dalam menggunakan sistem informasi dosen, tahun 2017 peneliti menganalisis sistem informasi dosen dengan metode (EUCS) End User Computing Satisfaction yang mencakup 5 variabel, dan 
pada tahun 2018 peneliti menganalisis menggunakan metode (Servqual) Service Quality. Persamaan terhadap analisis penelitian ini dengan yang telah dilakukan sebelumnya terdapat pada kesamaan mengukur tingkat kepuasan pengguna, sedangkan perbedaan analisis terhadap penelitian ini dengan yang dilakukan sebelumnya terletak pada jumlah responden yang digunakan, hasil akhir dan penggunaaan metode yang berbeda, yang dimana pada penelitian pertama menggunakan 100 responden mendapatkan hasil bahwa pengguna merasa cukup puas menggunakan sistem informasi dosen dengan kriteria kepuasan diatas 3,1 pada variabel content 3.8 , accuracy 3.8 , format 3.7, ease of use 3.6, dan time lines 3.7. Penelitian setelahnya dengan 40 responden menggunakan metode Service Quality (Servqual) menyatakankan hasil jika pengguna merasa kurang puas pada penggunaan sistem informasi dosen, hal tersebut diukur dari 5 variabel yang digunakan hanya 2 yang menyatakan puas dan 3 variabel menyatakan kuang dengan hasil rincian tangible 26.5, reliability 23 , responsiveness 3.1 , assurance 5,9, dan empathy 81,5.

Berdasarkan pembahasan dan uraian diatas maka diperlukannya penelitian evaluasi dengan menggunakan metode yang belum pernah digunakan terhadap sistem informasi dosen sebelumnya. Hal ini dilakukan untuk mengetahui hasil pembahasan dan validitas yang berbeda dengan tujuan untuk meminimalkan permasalahan dalam menerapkan sistem informasi dosen kedepannya. Hasil dari analisis tersebut memberikan perolehan nilai tingkat kepuasan dari setiap masing-masing variabel, didapatlah hasil yang menunjukan tingkat kepuasan dari tanggapan pengguna menggunakan sistem informasi dosen. Setelah mendapatkan hasil maka kemudian diberikan rangkuman rekomendasi pertimbangan perbaikan yang didasari dari responden yang memberikan tanggapan nilai terkecil dari masing-masing variabel dan sub variabel. Rangkuman rekomendasi diberikan untuk meningkatkan kualitas penerapan layanan teknologi informasi pendidikan yaitu sistem informasi dosen yang ada pada ITB STIKOM BALI.

\section{STUDI LITERATUR}

\section{A. SISTEM INFORMASI}

Kamus Besar Bahasa Indonesia (1995:50) menyebutkan jika sistem memiliki dua pengertian [1].
1. Suatu totalitas yang terbentuk dari kaitan teratur seperangkat unsur yang saling berkaitan.

2. Susunan asas, teori, dan sebagainya yang teratur dari pandangan.

Disebutkan juga oleh James A. Hall (2001), "sistem adalah kaitan antara dua atau lebih kelompok komponen yang saling terkait (interrelated) atau juga dari subsistemsubsistem yang menyatu untuk tercapainya tujuan yang sama (common purpose)". Dapat dilihat pendefinisian suatu sistem yaitu dari dua komponen atau lebih bahkan juga subsistem yang menyatu sebagai suatu kesatuan yang saling berinteraksi untuk tujuannya [2].

Disebutkan oleh Tata Sutabri, "Informasi adalah klasifikasi atau olahan data yang di interprestasikan untuk dapat membantu pengguna dalam proses pengambilan keputusan-keputusan. Pengolahan informasi tersebut nantinya akan memilah data tak berguna menjadi berguna untuk penerima [3].

Disebutkan juga informasi adalah pengolahan atau pengklasifikasian data untuk dapat membantu pengambilan keputusan. (Tata Sutarbi 2012:22) [4].

Awalan dari kata inform artinya adalah bentuk yang diberikan, dan kata informasi lebih kepada membentuk penerima informasi tersebut, seperti untuk pembentukan wawasan seseorang menjadi lebih berbeda (sebelum menerima informasi) [5].

Sistem informasi secara lebih detil, didefinisikan sebagai kumpulan perangkat entitas yang mencakup dari software, hardaware, dan brainware terkait dan saling bekerjasama untuk memberikan data yang bermanfaat dan berguna untuk penerimanya [6].

Kualitas sistem merupakan hal relatif yang dirasakan dari tingkat seberapa besar kemudahan, memahami, dan menggunakan teknologi komputer. Hal tersebut akan memperlihatkan jika pengguna merasa penggunaan sistem tersebut terbilang mudah, dan tidak banyak upaya yang harus dilakukan saat mengoprasikannya, sehingga pengguna memiliki banyak waktu untuk meningkatkan kinerjanya [7].

Dalam Davis et al. (1989) dan Chin dan Todd (1995) juga mendefinisikan jika kualitias suatu sistem informasi dari dianggap mudahnya untuk dimengerti dan dioprasikan. Hal tersebut menunjukan jika penggunaan suatu sistem terasa mudah, sehingga pengguna tidak perlu melakukan upaya dalam menjalankannya [8].

Sistem informasi dikemukakan John Burch dan Gary Grudnitski adalah bentukan dari beberapa komponen yang biasa disebutnya 
building block (blok bangunan), yang dimana mencakup blok masukan, blok model, blok keluaran, blok teknologi, blok kendali dan blok basis data. Dari masing-masing keenam blok tersebut akan saling berinteraksi untuk menjadi suatu kesatuan guna mencapai tujuannya [9].

Pada umumnya tujuan dari pembuatan sebuah sistem informasi tertentu dari setiap perusahaan adalah untuk mempermudah kinerja perusahaan seperti dalam pengolahan data akutansi perusahaan tersebut. Dijelaskan juga oleh Susanto (2013:8) secara umum sistem informasi berfungsi untuk.

1. Untuk mendukung aktivitas kinerja

keseharian perusahaan.

2. Untuk membantu proses pengambilan

keputusan perusahaan.

3. Untuk membantu dalam pertanggung

jawaban pengelola kepada pihak diluar perusahaan [10].

Pada fungsi dasarnya sistem informasi dibuat dan digunakan untuk mengolah data hingga mendapatkan informasi yang empunyai nilai dan bermanfaat untuk penerimanya, dalam menghasilkan sebuah informasi sangat diperluk an menjelaskan terjadinya siklus apa saja didala mnya hingga informasi itu dihasilkan.

Disebutkan oleh Mulyadi (2007) sebagai peranan penting seperti dosen professional, penilaian kinerja dosen harus dan perlu dilakuka n. Perlu dilakukan pelaporan dan penilaian kinerja dan aktivitas yang secara berkala atau periodik guna untuk efektivitas operasional suatu organisasi, dan personalnya. Hal tersebut didasari dengan sasaran yang strategis, standar mutu, serta aturan kriteria yang sudah ditetapkan sebelumnya.

Pada Universitas dan perguruan tinggi penilaian dosen sangatlah diperlukan untuk mengetahui bagaimana dan seberapa besar tingkat kinerja dosen tersebut dalam mengerjak an kegiatan proses pembelajaran pada instansi tempat dosen tersebut mengajar [11].

\section{B. KEPUASAN}

Dikutip oleh Fandy (2000:147) Menurut Day (dalam Tse dan Wilson) menyatakan jika ketidakpuasan dan kepuasan pengguna atau pelanggan adalah dari setiap respon yang diberikan kepada evaluasi diskonfirmasi yang dirasakan dari harapan sebelumnya beserta kinerja suatu produk setelah digunakan [12].

Variabel yang dapat digunakan untuk mengukur penilian kualitas jasa dan pelayanan ada 2, yaitu yang pertama adalah (perceived service) jasa yang dirasakan, dan yang kedua adalah (expected service) jasa yang diharapkan. Kepuasan terlihat dari kesesuaian antara suatu pelayanan yang didapat dengan harapan [13].

Kepuasan juga disebutkan merupakan perasaan yang dirasakan disuatu keadaan tertentu saat mendapat hasil kinerja yang memenuhi semua harapannya [14].

\section{EVALUASI}

Evaluasi merupakan suatu proses yang sistematis untuk menentukan atau membuat keputusan [15].

Sedangkan ada juga yang mengemukakan untuk melakukan evaluasi dalam sebuah sistem atau perangkat lunak, terdapat beberapa cara [16].

a. Heuristic evaluation

b. Software guidelines

c. Cognitive walkthrough

d. Usability Testing

\section{USABILITY}

Pengertian usability itu senidiri berawal dari kata usable yang pada umumnya merupakan arti kata bisa digunakan secara baik. Sesuatu hal yang dapat dikategorikan berguna secara baik jika tidak terjadi atau dapat diminimalkan kegagalannya pada saat penggunaanya, serta memberi kepuasan dan manfaat kepada penggunanya. Pada usabilitas atau yang disebut kebergunaan dalam interaksi manusia dan komputer, selaras dengan kemudahan mendapatkan informasi yang diinginkan. Mengenai interface yang mudah digunakan pada umumnya terdapat pada halaman website agar bisa dipergunakan lebih efisien, mudah, serta emberikan pengalaman yang menyenangkan bagi penggunanya [17].

Dijelaskan juga bahwa usability dihubungkan dengan lima dimensi usability [18].

1. Learnability

2. Efficiency

3. Memorability

4. Errors

5. Satisfaction

\section{E. PIECES FRAMEWORK}

Metode PIECES framework merupakan metode analisis yang pada umumnya digunakan dalam mngklasifikasi suatu masalah yang timbul, peluang kinerja, dan arahan yang terdapat pada definisi analisa sistem dan perancangan sistem. Menggunakan metode ini dapat menghasilkan suatu bahasan baru yang nantinya akan dapat membantu pertimbangan didalam mengembangkan suatu sistem. Dalam metode PIECES pada setiap hurufnya memiliki arti penjelasannya masing-masing, setiap huruf tersebut adalah bagian dari variabel PIECES 
tersebut dan didalamnya memiliki sub variabelnya tersendiri yang dimana akan menjurus terhadap masalah yang akan difokuskan. Bagian-bagian tersebut adalah.

$\mathbf{P}($ Performance $)=$ kinerja sistem

I (Information) $=$ informasi yg disajikan

$\mathbf{E}$ (Economics) = keuntungan yg dapat diraih

C $($ Control) $=$ keamanan sistem

$\mathbf{E}($ Efficiency $)=$ efisiensi orang dan proses

$\mathbf{S}($ Service $)=$ layanan yang diberikan

Untuk mengevaluasi dan melakukan perbaikan sistem yang sudah ada, metode PIECES adalah metode yang bisa digunakan. Mengidentifikasi masalah didalam sebuah sistem informasi yang sudah ada, metode PIECES adalah salah satu dari sekian banyak metode yang bisa digunakan (Junaedi, 2018).

PIECES Framework juga dapat dikatakan sebagai metode yang diperuntukan dalam mengklasifikasi suatu masalah, peluang, serta arahan yang ada didalam definisi bagian analisa sistem dan perancangan sistem. Metode PIECES digunakan dengan harapan akan dapat menghasilkan dan memberikan penemuanpenemuan baru yang dapat memberikan solusi pertimbangan saat pengembangan suatu sistem. Variabel tampilan (performance), informasi (information/data), kontrol dan keamanan (control/security), efisiensi (efficiency), serta servis (service) yang terdapat dalam PIECES akan dibagi lagi menjadi beberapa kriteria [19].

\section{Performance (Kehandalan sistem)}

Dalam suatu sistem kemampuan kinerja dalam menyelesaikan tugas degan cepat untuk mencapai sasaran adalah suatu keharusan. Indikator-indikator berikut ini akan menunjukan kinerja sebuah sistem.

a. Throughput, periode waktu yang dibutuhkan untuk banyaknya kinerja akan menilai sistem.

b. Respon time, dimana mengukur ratarata delay antara dari respon transaksi dan transaksi tersebut.

c. Audibility, dimana dapatnya digunakan kecocokan pada keselarasan terhadap standar.

d. Kelaziman komunikasi, dimana dapat digunakannya kemampuan dari interface, bandwith, dan protokol.

e. Kelengkapan, adalah harapan tercapainya implementasi yang dapat memenuhi fungsi.

f. Konsistensi, pada seluruh pengembangan perangkat lunak, desain dan teknik dokumentasi harus seragam. g. Toleransi kesalahan, kerusakan yang akan timbul disaat sistem menemui kesalahan.

2. Information/data (keakuratan informasi)

Informasi adalah suatu hal yang penting karena user dan majaemen menyiapkan pergerakan selanjutnya dari informasi tersebut. User dan manajemen akan mendapat informasi yang tepat waktu, relevan, serta akurat sesuai dengan harapan apabila sistem menghasilkan informasi yang baik.

a Akurasi, informasi yang dihasilkan harus memiliki ketepatan dan keakuratan tinggi.

b. Relevansi informasi, informasi yang dihasilkan harus memiliki kepastian yang sesuai dengan kebutuhan.

c. Penyajian informasi, informasi yang disajikan harus dengan bentuk yng mudah diintepretasikan.

d. Fleksibilitas data, informasi yang dihasilkan harus sesuai dengan apa yang dibutuhkan.

3. Economic (Nilai ekonomis sistem)

Pemanfaatan informasi digunakan untuk memanfaatkan biaya. Kebutuhan informasi yang ekonomis harus ditingkatkan, beserta penurunan biaya-biaya yang terjadi.

a. Reusabilitas, pengupayaan dapatnya suatu bagian dari program digunakan lagi pada aplikasi lain.

b. Sumber daya, sumber daya manusia dan sumber daya ekonomi mencakup dari jumlah sumber daya untuk pengembangan sistem.

4. Control (Pengamanan serta pengendalian sistem)

Segi kemudahan akses, integritas sistem, dan analisis ini digunakan untuk perbandingan sistem yang telah dianalisis berdasarkan keamanan data.

a. Integritas, dapat mengontrol tingkat kesalahan akses perangkat lunak dan data dari orang yang tidak berhak.

b. Keamanan, memiliki keamanan untuk melindungi dan mengontrol program.

5. Efficiency (Tingkat keefisienan sistem)

Dapat menggunakan secara optimal keefisienan hubungan dengan sumber tersebut. Efisien atau tidaknya operasi pada suatu perusahaan pada umumnya didasari dari tugas dan tanggung jawab saat pengoprasian.

a. Usabilitas, upaya dari pengoprasian, mempelajari, menyiapkan inputan, serta menghasilkan suatu outputan pada sistem.

b. Maintainabilitas, upaya untuk melakukan pencarian serta 
memperbaiki kesalahan pada sebuah sistem.

6. Service (Pelayanan sistem)

Menunjukan kategori yang beragam dari tingkat pelayanan. Simbol kualitas dari sebuah sistem merupakan peningkatan kualitas layanan yang jauh lebih baik untuk user serta manajemen dari sebuah sistem.

a. Akurasi, kontrol dan komputasi yang teliti.

b. Reliabilitas, ukuran suatu program dapat dipercaya dalam mengerjakan fungsi yang diminta.

c. Kesederhanaan, dimana suatu program bisa dipahami dengan mudah tanpa menemukan kesulitan.

\section{METODE PENELITIAN}

Model konsep rancangan penelitian ini menggunakan model kuantitatif dengan ilmu statistik. Pengolahan data pada penelitian ini yaitu mengolah data pada kuesioner yang diberikan pada seluruh responden setelah didapat dari populasi dosen yang menggunakan sistem informasi dosen di ITB STIKOM BALI.
Tabel 1. Variabel dan Sub Variabel pada Kuesioner PIECES

\begin{tabular}{ccc}
\hline VARIABEL & NOMOR & SUB VARIABEL \\
\hline \multirow{3}{*}{ Performance } & 1 & Audabilitas \\
& 2 & Kelaziman \\
& 3 & komunikasi \\
& 4 & Telengkapan \\
Information & 1 & Akurasi \\
& 2 & Relevansi Informasi \\
& 3 & Fleksibelitas data \\
Economics & 4 & Penyajian informasi \\
& 1 & Reusabilitas \\
& 2 & efisiensi waktu dan \\
Control & 1 & tenaga \\
\hline \multirow{2}{*}{ Efficiency } & 2 & Integritas \\
& 1 & Keamanan \\
\hline \multirow{2}{*}{ Service } & 2 & Usabilitas \\
& 1 & Akurasi \\
& 2 & Reliabilitas \\
& 3 & Kesederhanaan
\end{tabular}
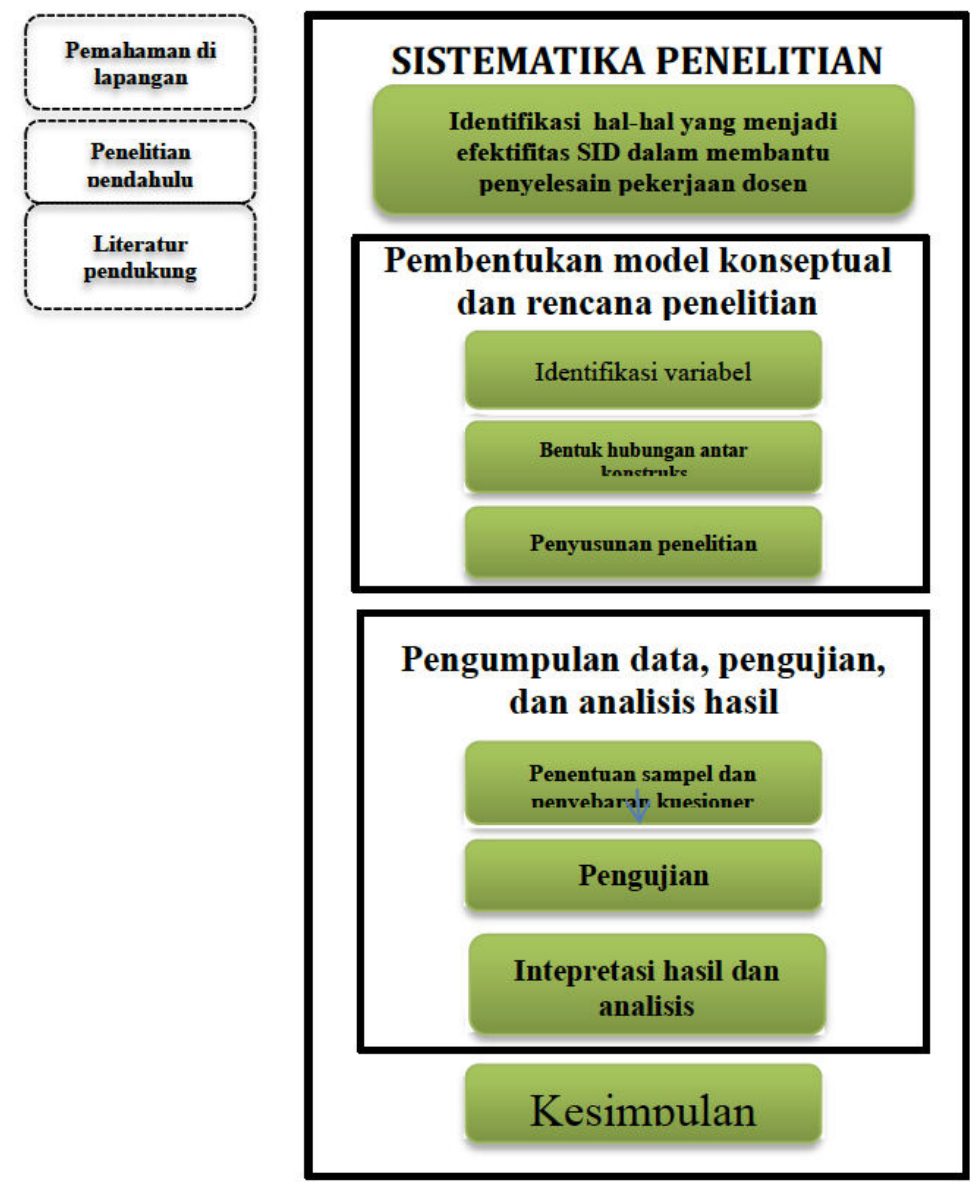

Gambar 1. Sistematika Penelitian

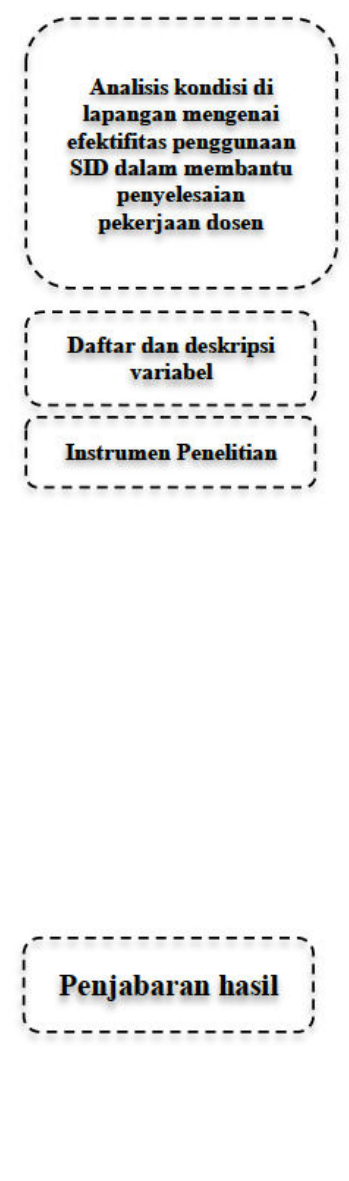


Sistematika penelitian ditunjukkan oleh Gambar 1. Masing-masing tahapan dapat dijelaskan sebagai berikut.

1. Mengidentifikasi penggunaan sistem informasi dosen mampu memberikan manfaat dalam pekerjaan dosen di bidang akademik. Proses ini dilaksanakan dengan melakukan pemahaman di lapangan, Studi literatur, dan studi penelitian pendahulu. Hasil dari proses ini adalah analisis terhadap hasil penggunaan sistem informasi dosen mampu memberikan manfaat dalam pekerjaan dosen dalam bidang akademik menjadi lebih baik.

2. Penentuan rancangan penelitian. Dalam tahap ini proses yang dilakukan adalah Identifikasi variabel, bentuk hubungan antar konstruk, serta penyusunan hasil dan kesimpulan penelitian. Faktor yang disusun dalam penelitian ini adalah dari kualitas tampilan, kualitas informasi, ekonomis, kontrol keamanan, efisiensi, serta kualitas layanan yang diberikan. Hasil dari tahap ini adalah daftar dan deskripsi variabel serta instrumen penelitian. Instrumen penelitian disesuaikan dengan deskripsi variabel penelitian.

3. Penyusunan instrumen pengumpulan data. Instrumen penelitian ini adalah kuesioner yang diberikan kepada seluruh sampel yang didapat dari seluruh populasi, namun sebelumnya dilakukan pengujian instrumen terlebih dahulu sebelum digunakan pada penelitian selanjutnya.

4. Pengujian kualitas instrumen untuk mengukur kelayakan terhadap kualitas instrumen disetiap pernyataan variabelnya, sebelum digunakan untuk pengumpulan data yang sebenarnya.

5. Penentuan populasi dan sampel untuk mendapat jumlah sampel yang diambil dan digunakan datanya setelah didapat dari populasi.

6. Pengumpulan data dilakukan dan diambil dari penyebaran kuesioner kepada seluruh sampel yang sudah didapat dari populasi.

7. Analisis data pengujian, serta interpretasi hasil pengujian. Hasil dari pengujian adalah penjabaran tingkat kepuasan pengguna dari masing-masing variabel.

8. Pengambilan rangkuman kesimpulan dan saran.

9. Proses terakhir adalah rekomendasi untuk perbaikan ke enam aspek variabel pada sistem informasi dosen yang mengacu dengan hasil penelitian menggunakan metode PIECES.
Rumus manual untuk menghitung ukuran sampel dari populasi yang sudah diketahui jumlahnya adalah sebagai berikut.

$\mathbf{S}=\frac{\chi^{2} \cdot N \cdot P \cdot Q}{d^{2}(N-1)+\chi^{2} \cdot P \cdot Q}$

Keterangan.

$\begin{array}{ll}\lambda^{2} & \text { : chi kuadrat dengan } \mathrm{dk}=1, \text { taraf } \\ & \text { kesalahan bisa } 1 \% 5 \% 10 \% \\ \mathrm{P} & =\mathrm{Q}=0,5 \text { (Proporsi Populasi) } \\ \mathrm{d} & : 0,05 \text { (derajat ketidaktelitian) } \\ \mathrm{S} & : \text { Jumlah Sampel } \\ \mathrm{N} & \text { : Jumlah Populasi }\end{array}$

Chi kuadrat : $\mathrm{dk}=1$ dengan taraf kesalahan $10 \%=2,706$ Populasi $(\mathrm{N})=155, \mathrm{P}=\mathrm{Q}=0.5, \mathrm{~d}$ $=0,05$

$$
\begin{aligned}
\mathbf{S} & =\frac{\chi^{2} \cdot N \cdot P \cdot Q}{d^{2}(N-1)+\chi^{2} \cdot P \cdot Q} \\
& =\frac{2,706^{*} 155^{*} 0,5^{*} 0,5}{(0,05)^{2}(155-1)+2,706^{*} 0,5^{*} 0,5} \\
& =\frac{104 \cdot 8575}{0,0025^{*} 154+0,6765} \\
& =\frac{104 \cdot 8575}{1,0615} \\
& =98,7=99 \text { (Pembulatan sampel) }
\end{aligned}
$$

\section{Responden Berdasarkan Jenis Kelamin}

Berdasarkan data yang berhasil dikumpulkan oleh peneliti, maka jumlah responden berdasarkan jenis kelamin adalah ditunjukkan oleh Tabel2.

Tabel 2. Responden Berdasarkan Jenis Kelamin Jumlah responden berdasarkan jenis kelamin

\begin{tabular}{ccc}
\hline Laki-Laki & 61 Orang & $65 \%$ \\
Perempuan & 32 Orang & $35 \%$ \\
Total & $\mathbf{9 3}$ Orang & $\mathbf{1 0 0 \%}$ \\
\hline
\end{tabular}

Untuk memudahkan mengamati jumlah tersebut, maka data divisualisasikan dalam bentuk diagram batang, seperti ditunjukkan pada Gambar 2. dimana responden Laki-Laki sebanyak $65 \%$ dan Perempuan sebanyak $35 \%$.Berdasarkan data tersebut, maka diketahui bahwa data yang dianalisis dalam penelitian ini sebagian besar berasal dari responden Pria. 


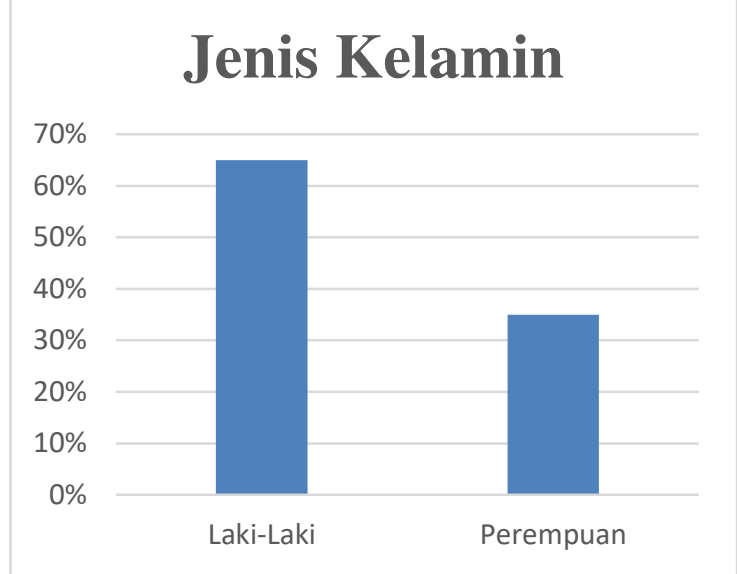

Gambar 2. Visualisasi Jumlah Responden Berdasarkan Jenis Kelamin

\section{Responden Berdasarkan Usia}

Berdasarkan data yang berhasil dikumpulkan oleh peneliti, maka jumlah responden berdasark an usia adalah ditunjukkan oleh Tabel 3.

Tabel 3. Responden Berdasarkan Usia

Jumlah responden berdasarkan Usia

\begin{tabular}{ccc} 
25-35 Tahun & 63 Orang & $68 \%$ \\
$36-50$ Tahun & 26 Orang & $28 \%$ \\
$>50$ Tahun & 4 Orang & $4 \%$ \\
Total & 93 Orang & $\mathbf{1 0 0 \%}$ \\
\hline
\end{tabular}

Untuk memudahkan mengamati jumlah tersebut, maka data divisualisasikan dalam bentuk diagram batang, seperti ditunjukkan pada Gambar 3.. dimana responden usia 25-35 tahun sebesar $68 \%$, usia $36-50$ tahun sebesar $28 \%$, dan usia $>50$ tahun sebesar $4 \%$. Berdasarkan data tersebut, maka diketahui bahwa data yang dianalisis dalam penelitian ini sebagian besar berusia 23-35 tahun.

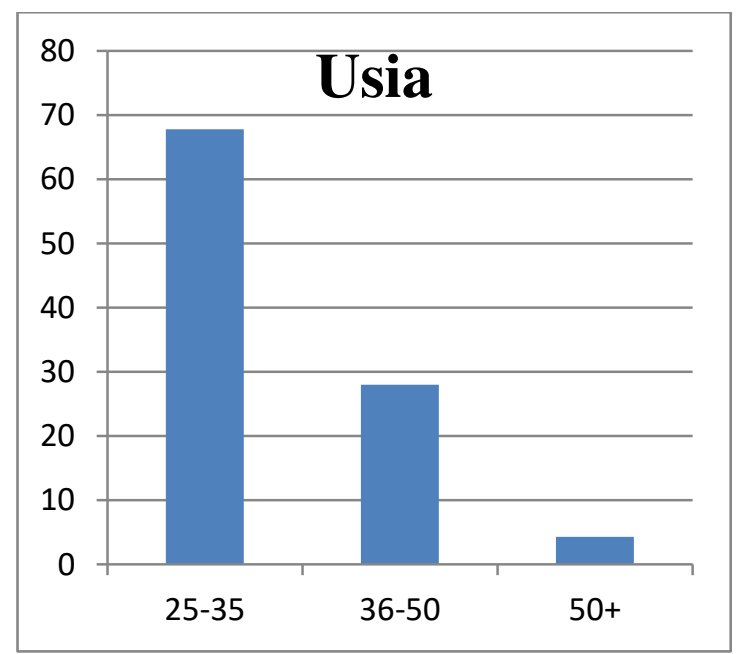

Gambar 3. Visualisasi Jumlah Responden Berdasarkan Usia

\section{Responden Berdasarkan Program Studi}

Berdasarkan data yang berhasil dikumpulkan oleh peneliti, maka jumlah responden berdasarkan program studi adalah ditunjukkan oleh Tabel .

Tabel 4. Responden Berdasarkan Program Studi

Jumlah responden berdasarkan Program Studi

\begin{tabular}{|c|c|c|}
\hline Sistem Komputer & 32 Orang & $34 \%$ \\
\hline Sistem Informasi & 52 Orang & $55 \%$ \\
\hline Teknologi Informasi & 3 Orang & $4 \%$ \\
\hline $\begin{array}{l}\text { Manajemen } \\
\text { Informatika }\end{array}$ & 6 Orang & $7 \%$ \\
\hline Total & 93 Orang & $100 \%$ \\
\hline
\end{tabular}

Untuk memudahkan mengamati jumlah tersebut, maka data divisualisasikan dalam bentuk diagram batang, seperti ditunjukkan pada Gambar 3. dimana responden program studi Sistem Komputer sebesar 34\%, Program Studi Sistem Informasi sebesar $55 \%$, program studi teknologi informasi sebesar $4 \%$ dan program studi manajemen informatika sebesar $7 \%$. Berdasarkan data tersebut, maka diketahui bahwa data yang dianalisis dalam penelitian ini sebagian besar berasal dari program studi Sistem Informasi.

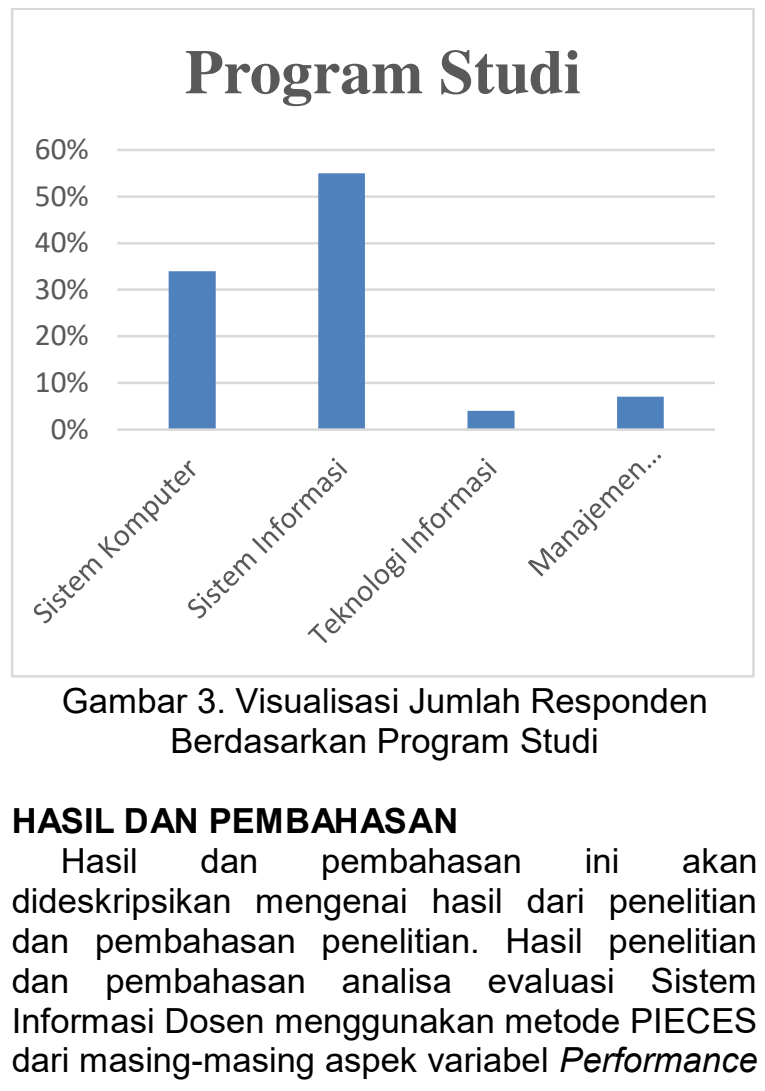


(Tampilan), Information (Informasi), Economics (Ekonomis), Control (Kontrol keamanan), Efficiency (Efisiensi), Service (Layanan) akan dilakukan secara akurat, aktual dan sistematis. adapun rincian dari masing-masing komponen tersebut dapat dijabarkan sebagai berikut.

Setelah dilakukan penghitungan dengan menggunakan metode perhitungan kepuasan yang dikembangkan oleh Kaplan dan Norton dimana dapat dilihat pada rumus di bawah ini.

$$
\mathrm{RK}=\frac{\mathrm{JSK}}{\mathrm{JK}}
$$

RK = (Rata-Rata Keputusan $)$

JSK = (Jumlah Skor Kuesioner $)$

$\mathrm{JK}=$ (Jumlah Kuesioner)

Berdasarkan perhitungan kepuasan seperti diatas untuk masing-masing variabel diperoleh hasil sebagai berikut, dengan acuan nilai skala likert (Sangat Setuju $=5$, Setuju $=4$, Cukup $=3$, Tidak Setuju=2 dan Sangat Tidak Setuju=1)

Tabel 5. Perhitungan Variabel Performance

\begin{tabular}{|c|c|c|c|c|c|c|}
\hline & KRITERIA & 5 & 4 & 3 & 2 & 1 \\
\hline P1 & $\begin{array}{l}\text { Pilihan menu yang } \\
\text { tersedia } \\
\text { memudahkan } \\
\text { pengoprasian SID }\end{array}$ & 37 & 49 & 6 & 1 & 0 \\
\hline P2 & $\begin{array}{lr}\text { Menu SID yang } \\
\text { disediakan dapat } \\
\text { dijalankan dengan } \\
\text { mudah } \\
\text { interaktif }\end{array}$ & 33 & 52 & 7 & 0 & 1 \\
\hline P3 & $\begin{array}{l}\text { Menu-menu yang } \\
\text { tersedia dapat } \\
\text { memunculkan } \\
\text { informasi lengkap } \\
\text { sesuai dengan } \\
\text { yang dibutuhkan }\end{array}$ & 29 & 54 & 9 & 1 & 0 \\
\hline P4 & $\begin{array}{l}\text { Terisedia instruksi } \\
\text { instruksi } \\
\text { pembatalan } \\
\text { perintah dengan } \\
\text { mudah mana kala } \\
\text { diperlukan }\end{array}$ & 28 & 42 & 19 & 3 & 1 \\
\hline & JUMLAH & 127 & 197 & 41 & 5 & 2 \\
\hline \multicolumn{7}{|c|}{$\begin{array}{l}\mathrm{RK} \\
=\underline{\mathrm{JSK}}(127 * 5)+(197 * 4)+(41 * 3)+(5 * 2)+(2 * 1)\end{array}$} \\
\hline
\end{tabular}

Berdasarkan hasil perhitungan rata-rata kepuasan pengguna pada variabel Performance (tampilan) didapatkan hasil 4.19. Setelah nilai akhir disesuaikan dengan karakteristik penilaian kepuasan oleh Kaplan dan Norton maka nilai 4.19 dikategorikan PUAS. Dapat disimpulkan bahwa kualitas pelayanan pada variabel Performance memberikan hasil puas kepada pengguna, dan menunjukkan indikasi positif bahwa Sistem Informasi Dosen berperan baik pada kualitas Performance (tampilan pada SID) yang diterapkan oleh ITB STIKOM Bali.

Tabel 6. Perhitungan Variabel Information

\begin{tabular}{|c|c|c|c|c|c|c|}
\hline & KRITERIA & 5 & 4 & 3 & 2 & 1 \\
\hline & SID memberikan & & & & & \\
\hline 11 & $\begin{array}{l}\text { informasi yang } \\
\text { lengkap, tepat, } \\
\text { dan akurat }\end{array}$ & 35 & 44 & 12 & 2 & 0 \\
\hline & $\begin{array}{l}\text { Informasi yang } \\
\text { terdapat dalam }\end{array}$ & & & & & \\
\hline 12 & $\begin{array}{l}\text { SID saat ini } \\
\text { relevan dengan } \\
\text { informasi } \\
\text { sebelumnya }\end{array}$ & 36 & 41 & 15 & 1 & 0 \\
\hline 13 & $\begin{array}{lr}\text { Informasi } & \text { pada } \\
\text { SID } & \text { mudah } \\
\text { didapat } & \text { dan } \\
\text { dicerna } & \end{array}$ & 37 & 44 & 10 & 2 & 0 \\
\hline & $\begin{array}{ll}\text { Informasi } & \text { pada } \\
\text { SID } & \text { selalu }\end{array}$ & & & & & \\
\hline 14 & $\begin{array}{l}\text { berkembang } \\
\text { sesuai } \\
\text { kebutuhan }\end{array}$ & 26 & 43 & 20 & 3 & 1 \\
\hline & JUMLAH & 134 & 172 & 57 & 8 & 1 \\
\hline
\end{tabular}

RK

$$
\begin{aligned}
& =\frac{\text { JSK: }(134 * 5)+(172 * 4)+(57 * 3)+(8 * 2)+(1 * 1)}{\text { JK: } 134+172+57+8+1} \\
& \text { RK }=\frac{1546}{372}=4.16
\end{aligned}
$$

Berdasarkan hasil perhitungan rata-rata kepuasan pengguna pada variabel Information (informasi) didapatkan hasil 4.16. Setelah nilai akhir disesuaikan dengan karakteristik penilaian kepuasan oleh Kaplan dan Norton maka nilai 4.16 dikategorikan PUAS. Dapat disimpulkan bahwa kualitas pelayanan pada variabel Information memberikan hasil puas kepada pengguna, dan menunjukkan indikasi positif bahwa Sistem Informasi Dosen berperan baik pada kualitas Information (kualitas informasi yang diberikan SID) yang diterapkan oleh ITB

\begin{tabular}{|c|c|c|c|c|c|c|}
\hline \multicolumn{2}{|r|}{ KRITERIA } & 5 & 4 & 3 & 2 & 1 \\
\hline E1 & $\begin{array}{l}\text { SID mengurangi } \\
\text { biaya pelaksanaan } \\
\text { user karena dapat } \\
\text { di akses dari mana } \\
\text { saja diberbagai } \\
\begin{array}{lr}\text { aplikasi dengan } \\
\text { jaringan }\end{array}\end{array}$ & 41 & 38 & 12 & 2 & 0 \\
\hline E2 & $\begin{array}{l}\text { Dengan } \\
\text { menggunakan } \\
\text { aplikasi SID, } \\
\text { pekerjaan menjadi } \\
\text { lebih mudah } \\
\text { diselesaikan } \\
\text { (efisiensi waktu } \\
\text { dan tenaga) }\end{array}$ & 41 & 36 & 14 & 2 & 0 \\
\hline JUN & $\mathrm{AH}$ & 82 & 74 & 26 & 4 & 0 \\
\hline
\end{tabular}
STIKOM Bali.

Tabel 7. Perhitungan Variabel Econommics 
RK

$=\frac{\text { JSK: }(82 * 5)+(74 * 4)+(26 * 3)+(4 * 2)+(0 * 1)}{\text { JK: } 82+74+26+4+0}$
$\mathrm{RK}=\frac{792}{186}=4.26$

Berdasarkan hasil perhitungan rata-rata kepuasan pengguna pada variabel Economics (keekonomisan) didapatkan hasil 4.26. Setelah nilai akhir disesuaikan dengan karakteristik penilaian kepuasan oleh Kaplan dan Norton maka nilai 4.26 dikategorikan PUAS. Dapat disimpulkan bahwa kualitas pelayanan pada variabel Economics memberikan hasil puas kepada pengguna, dan menunjukkan indikasi positif bahwa Sistem Informasi Dosen berperan baik pada kualitas Economics (sudut pandang keekonomisan menggunakan SID) yang diterapkan oleh ITB STIKOM Bali.

Tabel 8. Perhitungan Variabel Control

\begin{tabular}{clccccc}
\hline & KRITERIA & $\mathbf{5}$ & $\mathbf{4}$ & $\mathbf{3}$ & $\mathbf{2}$ & $\mathbf{1}$ \\
\hline $\mathrm{C} 1$ & $\begin{array}{l}\text { Program tidak } \\
\text { pernah mengalami } \\
\text { kesalahan saat }\end{array}$ & 15 & 35 & 33 & 8 & 2 \\
digunakan \\
$\begin{array}{l}\text { Data yang sudah } \\
\text { ada tidak dapat } \\
\text { diubah } \\
\text { pengguna oleh } \\
\text { (keamanan data } \\
\text { terjamin) }\end{array}$ & d3 & 41 & 18 & 1 & 0 \\
JUMLAH & & $\mathbf{4 8}$ & $\mathbf{7 6}$ & $\mathbf{5 1}$ & $\mathbf{9}$ & $\mathbf{2}$ \\
\hline
\end{tabular}

RK

$=\frac{\text { JSK: }(48 * 5)+(76 * 4)+(51 * 3)+(9 * 2)+(2 * 1)}{\text { JK: } 48+76+51+9+2}$ $\mathrm{RK}=\frac{717}{186}=3.85$

Berdasarkan hasil perhitungan rata-rata kepuasan pengguna pada variabel Control (kontrol dan keamanan) didapatkan hasil 3.85. Setelah nilai akhir disesuaikan dengan karakteristik penilaian kepuasan oleh Kaplan dan Norton maka nilai 3.85 dikategorikan PUAS. Dapat disimpulkan bahwa kualitas pelayanan pada variabel Control memberikan hasil puas kepada pengguna, dan menunjukkan indikasi positif bahwa Sistem Informasi Dosen berperan baik pada kualitas Control (kontrol dan keamanan pada data SID) yang diterapkan oleh ITB STIKOM Bali.

Berdasarkan hasil perhitungan rata-rata kepuasan pengguna pada variabel Efficiency (keefisienan) didapatkan hasil 4.23. Setelah nilai akhir disesuaikan dengan karakteristik penilaian kepuasan oleh Kaplan dan Norton maka nilai 4.23 dikategorikan PUAS. Dapat disimpulkan bahwa kualitas pelayanan pada variabel Efficiency memberikan hasil puas kepada pengguna, dan menunjukkan indikasi positif bahwa Sistem Informasi Dosen berperan baik pada kualitas Efficiency (keefisienan menggunakan SID) yang diterapkan oleh ITB STIKOM Bali.

Tabel 9. Perhitungan Variabel Efficiency

\begin{tabular}{clccccc}
\hline KRITERIA & $\mathbf{5}$ & $\mathbf{4}$ & $\mathbf{3}$ & $\mathbf{2}$ & $\mathbf{1}$ \\
\hline EF1 & $\begin{array}{l}\text { SID mudah untuk } \\
\text { dipelajari dan } \\
\text { dioperasikan }\end{array}$ & 47 & 38 & 5 & 3 & 0 \\
$\begin{array}{l}\text { Pengguna mudah } \\
\text { dalam }\end{array}$ & $\begin{array}{l}\text { memperbaiki data } \\
\text { saat terjadi } \\
\text { kesalahan input }\end{array}$ & 32 & 41 & 15 & 4 & 1 \\
\hline JUMLAH & $\mathbf{7 9}$ & $\mathbf{7 9}$ & $\mathbf{2 0}$ & $\mathbf{7}$ & $\mathbf{1}$ \\
\hline
\end{tabular}

RK

$=\frac{\text { JSK: }(79 * 5)+(79 * 4)+(20 * 3)+(7 * 2)+(1 * 1)}{\text { JK: } 79+79+20+7+1}$
$\mathrm{RK}=\frac{786}{186}=4.23$

Tabel 10. Perhitungan Variabel Service

\begin{tabular}{|c|c|c|c|c|c|c|}
\hline & KRITERIA & 5 & 4 & 3 & 2 & 1 \\
\hline S1 & $\begin{array}{l}\text { Kebutuhan } \\
\text { informasi } \\
\text { akademis yang } \\
\text { dibutuhkan dosen } \\
\text { terpenuhi melalui } \\
\text { SID }\end{array}$ & 30 & 48 & 12 & 3 & 0 \\
\hline S2 & $\begin{array}{l}\text { Aplikasi } \\
\text { memberikan } \\
\text { informasi } \\
\text { terpercaya yang } \\
\text { relevan dengan } \\
\text { aturan }\end{array}$ & 40 & 40 & 11 & 2 & 0 \\
\hline S3 & $\begin{array}{l}\text { Tata letak navigasi } \\
\text { dan tampilan SID } \\
\text { mudah dipahami } \\
\text { pengguna }\end{array}$ & 40 & 40 & 9 & 2 & 2 \\
\hline JUM & $\mathrm{AH}$ & 110 & 128 & 32 & 7 & 2 \\
\hline
\end{tabular}

RK

$=\frac{\text { JSK: }(110 * 5)+(128 * 4)+(32 * 3)+(7 * 2)+(2 * 1)}{\text { JK: } 110+128+32+7+2}$ $\mathrm{RK}=\frac{1174}{279}=4.21$

Berdasarkan hasil perhitungan rata-rata kepuasan pengguna pada variabel Service (layanan) didapatkan hasil 4.21. Setelah nilai akhir disesuaikan dengan karakteristik penilaian kepuasan oleh Kaplan dan Norton maka nilai 4.21 dikategorikan PUAS. Dapat disimpulkan bahwa kualitas pelayanan pada variabel Service memberikan hasil puas kepada pengguna, dan menunjukkan indikasi positif bahwa Sistem Informasi Dosen berperan baik pada kualitas Service (pelayanan yang diberikan oleh SID) yang diterapkan oleh ITB STIKOM Bali. 
Dari 6 (Enam) variabel yang sudah dihitung dengan formula PIECES, yang diamana untuk menentukan tingkat kepuasan menggunakan model yang didefinisikan oleh Kaplan dan Norton adalah dengan tingkatan sebagai berikut.

$$
\begin{array}{ll}
1-1.79 & =\text { Sangat Tidak Puas } \\
1.8-2.59 & =\text { Tidak Puas } \\
2.6-3.39 & =\text { Ragu-Ragu } \\
3.4-4.91 & =\text { Puas } \\
4.92-5 & =\text { Sangat Puas }
\end{array}
$$

Tabel 11. Hasil Perhitungan Semua Variabel

\begin{tabular}{ccc}
\hline Variable & Rata-Rata Kepuasan & Kategori \\
\hline Performance & 4.19 & PUAS \\
Information & 4.16 & PUAS \\
Economics & 4.26 & PUAS \\
Control & 3.85 & PUAS \\
Security & 4.23 & PUAS \\
Efficiency & 4.21 & PUAS \\
Service & &
\end{tabular}

Dari hasil penghitungan PIECES, dapat dilihat bahwa penggunaan Sistem Informasi Dosen berdampak positif dimana dari hasil penghitungan seluruh variabel memberikan kategori PUAS dengan rata-rata kepuasan $>=3.4-4.91$.

\section{Rekomendasi Evaluasi Sistem Informasi Dosen}

Pada hasil evaluasi sistem informasi dosen menggunakan metode PIECES sudah dinyatakan bahwa analisis mendapat nilai rata-

\begin{tabular}{|c|c|c|c|c|}
\hline \multicolumn{2}{|r|}{ KRITERIA } & TS & STS & NILAI \\
\hline P1 & $\begin{array}{l}\text { Pilihan menu yang tersedia } \\
\text { memudahkan pengoprasian } \\
\text { SID }\end{array}$ & 1 & 0 & $2.2 \%$ \\
\hline P2 & $\begin{array}{l}\text { Menu SID yang disediakan } \\
\text { dapat dijalankan dengan } \\
\text { mudah dan interaktif }\end{array}$ & 0 & 1 & $1.1 \%$ \\
\hline P3 & $\begin{array}{l}\text { Menu-menu yang tersedia } \\
\text { dapat memunculkan informasi } \\
\text { lengkap sesuai dengan yang } \\
\text { dibutuhkan }\end{array}$ & 1 & 0 & $2.2 \%$ \\
\hline P4 & $\begin{array}{l}\text { Terisedia instruksi instruksi } \\
\text { pembatalan perintah dengan } \\
\text { mudah mana kala diperlukan }\end{array}$ & 3 & 1 & $7.5 \%$ \\
\hline & JUMLAH & 5 & 2 & $3.2 \%$ \\
\hline
\end{tabular}
rata yang dikatakan puas pada kriteria penilaian kepuasan, namun masih didapat hasil yang tidak puas dari para responden pada beberapa sub variabel.

Berikut penjabaran hasil nilai tanggapan responden yang tidak puas serta rangkuman rekomendasi dari setiap masing-masing variabel pada tabel-tabel berikut ini.

Tabel 12. Perhitungan Variabel Performance
Pada variabel Performance menyatakan bahwa ada total 7 responden yang menyatakan tanggapan nilai tidak setuju 5 responden dan sangat tidak setuju 2 responden. Tanggapan itu diberikan karena fitur-fitur menu terlalu padat, posisinya bertumpukan, dan ukuran tulisan yang cenderung kecil pada sistem informasi dosen. Oleh karena itu, direkomendasikan untuk menyederhanakan tampilan fitur-fitur menu dan menggeser menjadi sub-men serta memperbesar ukuran hurufnya.

Selain itu, ada beberapa dosen yang belum paham memanfaatkan beberapa fitur pada sistem informasi dosen, khususnya yang mengampu mata kuliah yang non IT. Oleh karena itu, direkomendasikan untuk melakukan pelatihan menggunakan sistem informasi dosen terhadap dosen yang sudah berumur, dosen baru dan dosen yang mengajar non IT, agar dapat memanfaatkan penggunaan sistem informasi dosen lebih baik lagi.

Tabel 13. Perhitungan Variabel Information

\begin{tabular}{clcccc}
\hline \multicolumn{2}{c}{ KRITERIA } & TS & STS & NILAI \\
\hline I1 & $\begin{array}{l}\text { SID memberikan informasi } \\
\text { yang lengkap, tepat, dan } \\
\text { akurat }\end{array}$ & 2 & 0 & $4.3 \%$ \\
Informasi yang terdapat & $\begin{array}{l}\text { Inf } \\
\text { dalam SID saat ini relevan } \\
\text { dengan informasi sebelumnya } \\
\text { Informasi pada SID mudah } \\
\text { didapat dan dicerna } \\
\text { Informasi pada SID selalu } \\
\text { berkembang } \\
\text { kebutuhan }\end{array}$ & 2 & 0 & $2.2 \%$ \\
\hline JUMLAH & $\mathbf{8}$ & $\mathbf{1}$ & $\mathbf{4 . 6 \%}$ \\
\hline
\end{tabular}

Pada variabel Information menyatakan bahwa ada total 9 responden yang menyatakan tanggapan nilai tidak setuju 8 responden dan sangat tidak setuju 1 responden. Tanggapan itu diberikan karena masih adanya kekurangan dalam cepatnya perkembangan informasi yang diberikan secara berkala oleh sistem informasi dosen. Oleh karena itu, direkomendasikan pada sistem informasi dosen untuk lebih cepat dan tanggap dalam melakukan perkembangan informasi terbaru secara cepat akurat, dan berkala

Pada variabel Econommics menyatakan bahwa ada total 4 responden yang menyatakan tanggapan nilai tidak setuju 4 responden dan sangat tidak setuju 0 responden. Tanggapan itu diberikan karena Masih ada beberapa keterlambatan dari beberapa fitur dan download link saat ingin mengakses dan mendapatkan informasi. Oleh karena itu, direkomendasikan pada sistem informasi dosen diharapkan agar dapat lebih cepat dalam mengakses dan 
memberikan informasi untuk membatu pekerjaan dosen pada proses perkuliahan.

Tabel 44. Perhitungan Variabel Econommics

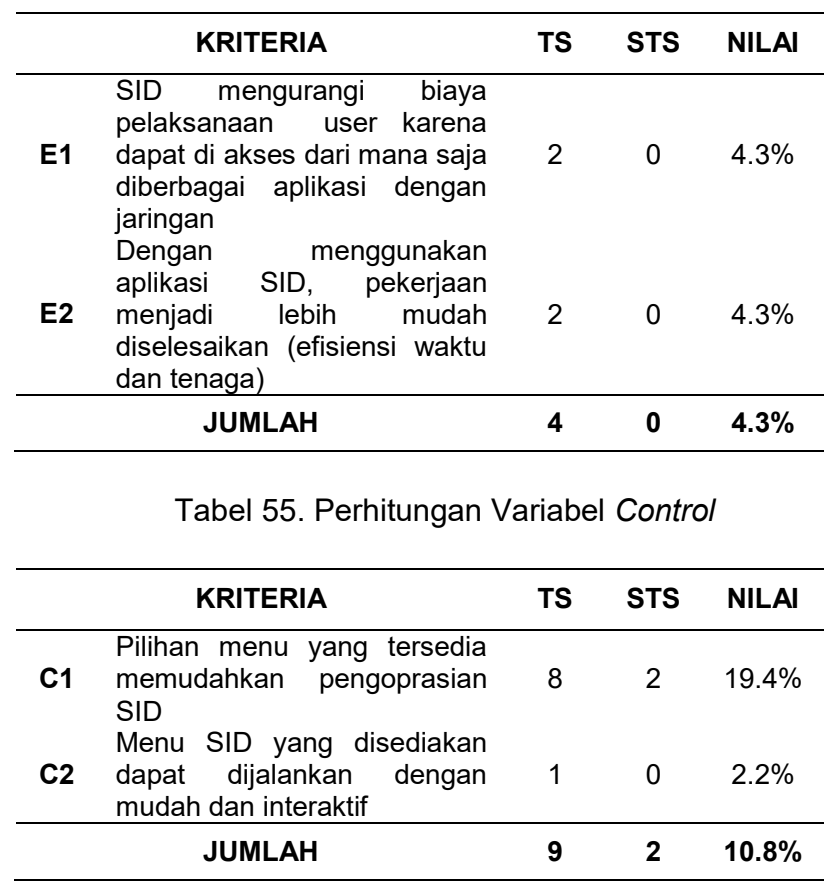

Pada variabel Control menyatakan bahwa ada total 11 responden yang menyatakan tanggapan nilai tidak setuju 9 responden dan sangat tidak setuju 2 responden. Tanggapan itu diberikan karena masih ada terjadinya error saat pengguna menggunakan sistem informasi dosen seperti terkadang ada beberapa fitur yang tidak bisa diakses saat digunakan bersamaan, sistem juga akan logout dengan sendirinya jika tidak di oprasikan beberapa menit. Oleh karena itu, direkomendasikan pada sistem informasi dosen agar sistem informasi dosen tidak mengalami error dibeberapa fitur saat digunakan bersamaan dan sistem informasi dosen tidak akan logout jika tidak di oprasikan selama beberapa menit agar pengguna tidak melakukan login ulang dan mengakses ulang informasi.

Tabel 66. Perhitungan Variabel Efficiency

\begin{tabular}{ccccc}
\hline \multicolumn{2}{c}{ KRITERIA } & TS & STS & NILAI \\
\hline EF & $\begin{array}{l}\text { SID mudah untuk dipelajari } \\
\text { dan dioperasikan }\end{array}$ & 3 & 0 & $6.5 \%$ \\
$\begin{array}{c}\text { EF } \\
\mathbf{2}\end{array}$ & $\begin{array}{l}\text { Pengguna mudah dalam } \\
\text { memperbaiki data saat } \\
\text { terjadi kesalahan input }\end{array}$ & 4 & 1 & $9.7 \%$ \\
\hline JUMLAH & $\mathbf{7}$ & $\mathbf{1}$ & $\mathbf{8 . 1 \%}$ \\
\hline
\end{tabular}

Pada variabel Efficiency menyatakan bahwa ada total 8 responden yang menyatakan tanggapan nilai tidak setuju 7 responden dan sangat tidak setuju 1 responden. Tanggapan itu diberikan karena Beberapa pengguna masih menemukan kesulitan pada saat perbaikan inputan jika terjadi kesalahan terutama saat penginputan tulisan yang panjang seperti pencarian judul TA/Skripsi dan kerja praktek. Oleh karena itu, direkomendasikan pada sistem informasi dosen agar sistem informasi dosen bisa dilengkapi pembetulan otomatis (autocorrect) terhadap kata kunci yang diinputkan.

Tabel 77. Perhitungan Variabel Service

\begin{tabular}{clccc}
\hline KRITERIA & TS & STS & NILAl \\
\hline S1 & $\begin{array}{l}\text { Kebutuhan } \\
\text { akademis yang dibutuhkan } \\
\text { dosen terpenuhi melalui SID }\end{array}$ & 3 & 0 & $6.5 \%$ \\
S2 & $\begin{array}{l}\text { Aplikasi SID memberikan } \\
\text { informasi terpercaya yang } \\
\text { relevan dengan aturan }\end{array}$ & 2 & 0 & $4.3 \%$ \\
S3 & $\begin{array}{l}\text { Tata letak navigasi dan } \\
\text { tampilan SID mudah } \\
\text { dipahami penguna }\end{array}$ & 2 & 2 & $6.5 \%$ \\
\hline JUMLAH & $\mathbf{7}$ & $\mathbf{2}$ & $\mathbf{5 . 7 \%}$ \\
\hline
\end{tabular}

Pada variabel Service menyatakan bahwa ada total 9 responden yang menyatakan tanggapan nilai tidak setuju 7 responden dan sangat tidak setuju 2 responden. Tanggapan itu diberikan karena masih adanya beberapa informasi penting dan wajib yang belum tersedia pada sistem informasi dosen, hal tersebut membuat dosen masih harus mencari informasi terkait pada bagian akademik dan sistem informasi lainnya. Oleh karena itu, direkomendasikan pada sistem informasi dosen untuk menambahkan fitur-fitur informasi wajib tersebut pada sistem informasi dosen seperti dengan fitur jadwal penelitian dan pengabdian, fitur upload dan history penelitian serta pengabdian, fitur rekapitulasi kehadirandosen.

\section{KESIMPULAN}

Berdasarkan hasil penelitian yang dilakukan mengenai "Evaluasi Sistem Informasi Dosen pada ITB STIKOM BALI menggunakan metode (PIECES) Performance Information Economics Control Efficiency and Service" untuk sistem informasi dosen pada ITB STIKOM BALI dapat disimpulkan sebagai berikut.

1. Teknik perhitungan metode PIECES dapat diterapkan dengan baik untuk analisis evaluasi kepuasan penggunaan sistem informasi dosen pada ITB STIKOM BALI. Analisis evaluasi pada sistem informasi dosen telah menghasilkan kesimpulan bahwa tampilan pada sistem informasi dosen, kualitas informasi pada sistem 
informasi dosen, keekonomisan menggunakan sistem informasi dosen, keamanan kontrol menggunakan sistem informasi dosen, keefisienan penerapan sistem informasi dosen, dan segi kualitas layanan pada sistem informasi dosen berada pada rata-rata nilai kriteria kepuasan 3.4 - 4.91 yang menyatakan bahwa pengguna merasa puas menggunakan sistem informasi dosen dalam meningkatkan kemudahan kinerja.

2. Telah didapatkan hasil nilai kepuasan analisis evaluasi dari variabel performance tampilan pada sistem informasi dosen 4,19, information kualitas informasi pada sistem informasi dosen 4,16, econommics keekonomisan menggunakan sistem informasi dosen 4,26, control keamanan kontrol menggunakan sistem informasi dosen 3,85, efficiency keefisienan penerapan sistem informasi dosen 4,23, dan service segi kualitas layanan sistem informasi dosen 4,21 pada penggunaan sistem informasi dosen ITB STIKOM BALI menggunakan metode PIECES..

3. Telah didapatkan hasil rekomendasi perbaikan pada analisis evaluasi terhadap sistem informasi dosen. Rekomendasi diberikan berdasarkan tanggapan terkecil dari responden disetiap variabel dan sub variabel. Hasil rincian menunjukan pada performance tampilan pada sistem informasi dosen $3,2 \%$, information kualitas informasi pada sistem informasi dosen 4,6\%, econommics keekonomisan menggunakan sistem informasi dosen 4,3\%, control keamanan kontrol menggunakan sistem informasi dosen 10,8\%, efficiency keefisienan penerapan sistem informasi dosen $8,1 \%$, dan dari service segi kualitas layanan $5,7 \%$ pada penggunaan sistem informasi dosen ITB STIKOM BALI.

\section{SARAN}

Berikut ini adalah saran dari pengamatan penulis mengenai beberapa hal yang menjadi bahan pertimbangan untuk dapat dikembangkan kedepannya.

Diharapkan pengembangan selanjutnya dapat lebih mengoptimasi analisis sistem informasi dosen seperti dengan cara membandingkan teknik ini dengan teknik lainya atau menggunakan perhitungan metode yang lain. Hal tersebut guna untuk mengetahui teknik mana yang jauh lebih baik dan lebih efisien dalam mengoptimasi analisis evaluasi sistem informasi dosen pada ITB STIKOM BALI.

Bagi penelitian selanjutnya, perlu ditambahkan teknik untuk mengukur aspek penting usability seperti kebiasaan mengunjungi suatu sistem (learnability) dan mudah diingat (memorability). Agar perkembangan sistem informasi dosen kedepannya lebih baik lagi dan lebih sangat membantu pekerjaan para dosen di ITB STIKOM BALI sehingga hasil penelitian lebih mendetail mengenai indikator apa saja yang perlu mendapat perhatian lebih.

Hasil data analisis evaluasi sistem informasi dosen yang diperoleh saat ini merupakan penerapan dari metode PIECES yang terfokus kepada tampilan sistem informasi dosen, kualitas informasi pada sistem informasi dosen, keekonomisan menggunakan sistem informasi dosen, keamanan kontrol pada sistem informasi dosen, keefisienan penerapan sistem informasi dosen, dan segi kualitas layanan pada sistem informasi dosen ITB STIKOM BALI

\section{REFERENS}

[1] Ardi, S. \& B. K. (2014) 'Peranan Strategi Sistem Informasi Manajemen Untuk Mencapai Tujuan', Peran Strategi Sistem Informasi Manajemen, (36), pp. 1-14.

[2] Richki Hardi, H. (2017) 'Pengembangan Sistem Informasi Perpustakaan Menggunakan Kerangka Pieces (Studi Kasus Perpustakaan STITEK Bontang)', IImiah Teknologi Informasi Terapan, 1(3), pp. 15-21.

[3] Yusran, Y. (2020) 'Perancangan Sistem Informasi Administrasi Pembayaran SPP Siswa Berbasis Web', Edik Informatika, 6(2), pp. 7-14. doi: 10.22202/ei.2020.v6i2.3980.

[4] Wildaningsih, W. and Yulianeu, A. (2018) 'Sistem Informasi Pengolahan Data Anggota Unit Keagiatan Mahasiswa (UKM) Zaradika STMIK DCI Tasikmalaya', Jumantaka, 2(1), pp. 181190. Available at: http://jurnal.stmikdci.ac.id/index.php/jumantaka/article/view 1364.

[5] Aini, A. (2007) 'Sistem Informasi Geografis Pengertian dan Aplikasinya', Diakses Dari http://stmik. amikom. ac. id/[Diakses 24 Maret 2013].

[6] Herliana, A. and Rasyid, P. M. (2016) 'Sistem Informasi Monitoring Pengembangan Software Pada Tahap', Jurnal Informatika, (1), pp. 41-50.

[7] Rakhmadian, M. et al. (2017) 'Analisis Kualitas Sistem Dan Kualitas Informasi Terhadap Kepuasan Pemakai Sistem Informasi Akademik Dosen', Seminar Nasional Sistem Informasi, (September), pp. 665-675.

[8] Prayanthi, I., Lompoliu, E. and Langkedeng, R. D. (2020) 'Pengaruh 
Kualitas Sistem, Kualitas Informasi Dan Perceived Usefulness Terhadap Kepuasan Pengguna Sistem Informasi Akuntansi', Klabat Accounting Review, 1(2), p. 1. doi: 10.31154/kar.v1i2.475.111.

[9] Widiastuti, R. Y. (2011) 'Analisis Dan Perancangan Sistem Informasi Kependudukan Di Kecamatan Depok Yogyakarta', ILKOM Jurnal IImiah, 66(July), pp. 37-39.

[10] Purba, D. H. P., Ekonomi, F. and Indonesia, U. M. (2018) 'Jurnal manajemen', 4, pp. 15-22.

[11] Sari, R. E. and Saleh, A. (2016) 'Menggunakan Metode Ahp ( Studi Kasus: Di Stmik Potensi Utama Medan )', Stmik, pp. 108-114.

[12] Asbar, Y. and Saptari, M. A. (2017) 'Analisa Dalam Mengukur Kualitas Pelayanan Terhadap Kepuasan Konsumen Menggunakan Metode PIECES', Jurnal Visioner \& Strategis, 6(2), pp. 39-47.

[13] Abdurahman, D. and Ferga Prasetyo, T. (2016) 'Mengukur Tingkat Kepuasan Msahasiswa Dalam Pembelajaran Dengan Menggunakan Sistem Pakar (Studi Kasus: Mahasiswa Teknik Informatika)', J-Ensitec, 2(02), pp. 20-24. doi: 10.31949/j-ensitec.v2i02.303.

[14] Lokapitasari Belluano, P. L. et al. (2019) 'Analisis Tingkat Kepuasan Pengguna Sistem Informasi Perpustakaan Menggunakan Pieces Framework', ILKOM Jurnal IImiah, 11(2), pp. 118-128. doi: 10.33096/ilkom.v11i2.398.118-128.

[15] Wulan, A. R. (2007) 'Pengertian Dan Esensi Konsep', Jurnal FPMIPA Universitas Pendidikan Indonesia, pp. 112.

[16] Safarina, M. D. et al. (2014) 'Komparasi Effectiveness Dan Efficiency Pada Usability Testing Menggunakan Eye Tracking Comparasion Effectiveness and Efficiency on Usability Testing Use Eye Tracking and'.

[17] Handiwidjojo, W. and Ernawati, L. (2016) 'Pengukuran Tingkat Ketergunaan ( Usability ) Sistem Informasi Keuangan Studi Kasus: Duta Wacana Internal Transaction ( Duwit )', Juisi, 02(01), pp. 49-55. Available at: https://journal.uc.ac.id/index.php/JUISI/art icle/view/115.

[18] Joanna (Uiversitas Sebelas Maret) (2010) 'Penyusunan Usability Index Browser Internet'.

[19] Tullah, R. and Hanafri, M. I. (2014)
'Evaluasi Penerapan Sistem Informasi Pada Politeknik LP3I Jakarta Dengan Metode Pieces', Jurnal Sisfotek Global, $4(1)$, pp. 22-28. 